\title{
DESIGN OF ECCENTRICALLY CONNECTED CLEAT PLATES IN COMPRESSION
}

\author{
X.E. Khoo ${ }^{1}$, M. Perera ${ }^{2}$ and F. Albermani ${ }^{3, *}$ \\ ${ }^{1}$ Structural Engineer, Bonacci Group \\ ${ }^{2}$ Structural Engineer, Connell Wagner \\ ${ }^{3}$ Associate Professor, School of Civil Engineering, University of Queensland \\ *(Corresponding author: E-mail: f.albermani@uq.edu.au)
}

Received: 29 December 2008; Revised: 21 July 2009; Accepted: 17 August 2009

\begin{abstract}
The paper presents experimental results from twelve full scale test samples using different CHS member lengths and eccentric cleats combinations. The test results show that the governing connection failure is a sway collapse mechanism. Based on this evidence, a simple design method for eccentric cleat connection in compression is proposed. Results from the proposed design methods are in good agreement with the obtained experimental results and with FE predictions.
\end{abstract}

Keywords: Eccentric cleat connection, CHS member, design method

\section{INTRODUCTION}

Unlike open structural sections where it is possible to connect the structural member directly to a gusset plate, the connection of structural steel hollow sections require certain fabrication such as slotted-end plate, welded-tee and flattened-end connections. This paper deals with slotted-end plate connection type (Figure 1a). The end plate is commonly bolted through a cleat or a gusset plate to a supporting member. This will result in an eccentric connection with unavoidable bending stresses that adversely affect the connection capacity under compression. Although it is possible to eliminate the resulting eccentricity by using a more elaborate slotted-plates detailing (fork type, Figure 1b), this will increase fabrication cost. The slotted-end plate (Figure. 1a) remains the most common type of hollow section connection used in practice.
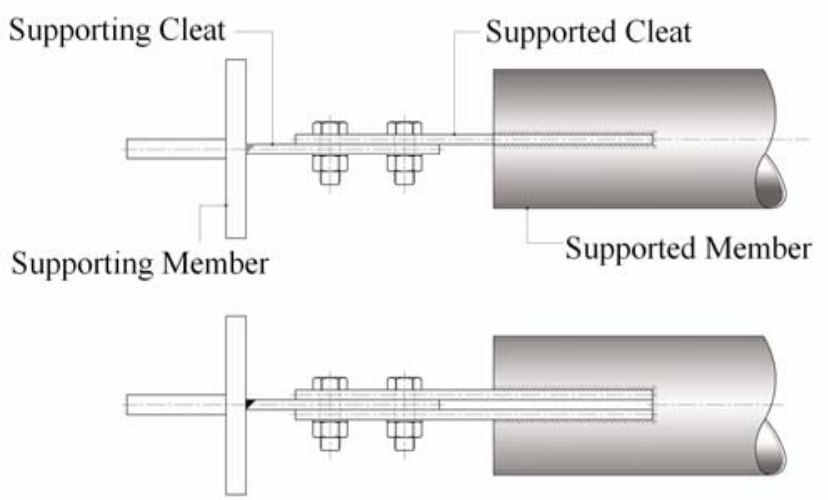

Figure 1a.

Traditional Slotted Cleat Connection

Figure 1b.

Slotted Fork Cleat Connection

The design of eccentric cleats is covered by a number of specifications [1-3] with a wide spectrum of design capacities determined according to these specifications. In Australia, the design of eccentric cleats is covered by the ASI guide [1]. The recommendations in this guide were based on experimental and analytical work presented by Kitipornchai et al. [4]. The work of Kitipornchai et al. identified three possible failure modes for a compression member with eccentrically connected cleat plates at both ends, these are: overall member buckling, connection failure with sway and 
connection failure without sway. They had shown that analysis based on the first-yield approach resulted in an overly conservative result while ignoring the eccentric moment generated in the cleat plates would result in unconservative design. Furthermore, they concluded that for most practical applications the relative bending stiffness between the cleat plate and the member to which the cleat is attached will approximate a fully fixed connection. Following this conclusion, they derived six possible plastic collapse mechanisms for the connection that were confirmed by experimental results conducted on isolated cleat plates. Based on this, a design method was proposed that was adopted by the Australian Steel Institute, ASI [1].

This design approach will overestimate the connection capacity if the connection fails in a sway rather than fully fixed mode. This was first recognized during the development of steel connection design software Limcon V3 [5]. In response to this, the ASI issued an advisory note [6] that recommended using the design procedures outlined in the Australian steel structures code [7] taking into account the combined bending and compression actions for designing eccentric cleat connections rather than using the ASI design guide [1].

More recently, New Zealand Heavy Engineering Research Association (HERA) recommended a new step-by-step design method for eccentric cleats [8]. This method suggests that the dominant failure mode of this type of connection is a sway mode. It assumes that at least one end of the overlapping cleat plates is effectively fully fixed while the connection to the end of the supported member can be free to translate. Particular attention is given to identifying the exact type of support conditions at both ends of the cleat plate. A procedure to determine whether a cleat is effectively fixed to the supported member is also outlined in this method.

Experimental study using scaled samples of members connected to eccentric cleats was recently carried out at the University of Sydney [9]. This study showed significant interaction between bending and compression in the cleat plates and the presence of significant sway in the tested samples.

In this paper the results obtained from full-scale experimental program using 12 samples of different member length and eccentric cleats combinations will be presented. The experimental results are compared with available design methods for eccentric cleat connections and with FE predictions and a new design procedure is proposed.

\section{EXPERIMENTAL RESULTS}

A total of twelve test specimens were used, three samples of each of the following member lengths $\left(\mathrm{L}_{\mathrm{b}}\right) ; 3 \mathrm{~m}, 4 \mathrm{~m}, 5 \mathrm{~m}, 6.5 \mathrm{~m}$. All the members were Grade 350 hot rolled circular hollow sections CHS with an outside diameter of $139.7 \mathrm{~mm}$ and a wall thickness of $3.5 \mathrm{~mm}$. Different member lengths were used in order to assess the effect of the relative stiffness of the overlapping cleats and the member on the design capacity of the connection.

A constant cleat length $\mathrm{Lc}=170 \mathrm{~mm}$ (Figure 2) was used for the $3 \mathrm{~m}$ and $6.5 \mathrm{~m}$ members. For the $4 \mathrm{~m}$ and $5 \mathrm{~m}$ length members, three different cleat lengths, Lc, were used. These were; $170 \mathrm{~mm}, 220 \mathrm{~mm}$ and $270 \mathrm{~mm}$. This was done in order to assess the effect of cleat plates' slenderness on the connection capacity while the member slenderness is kept constant. All cleat plates used were 180x10mm Grade 300 steel. 


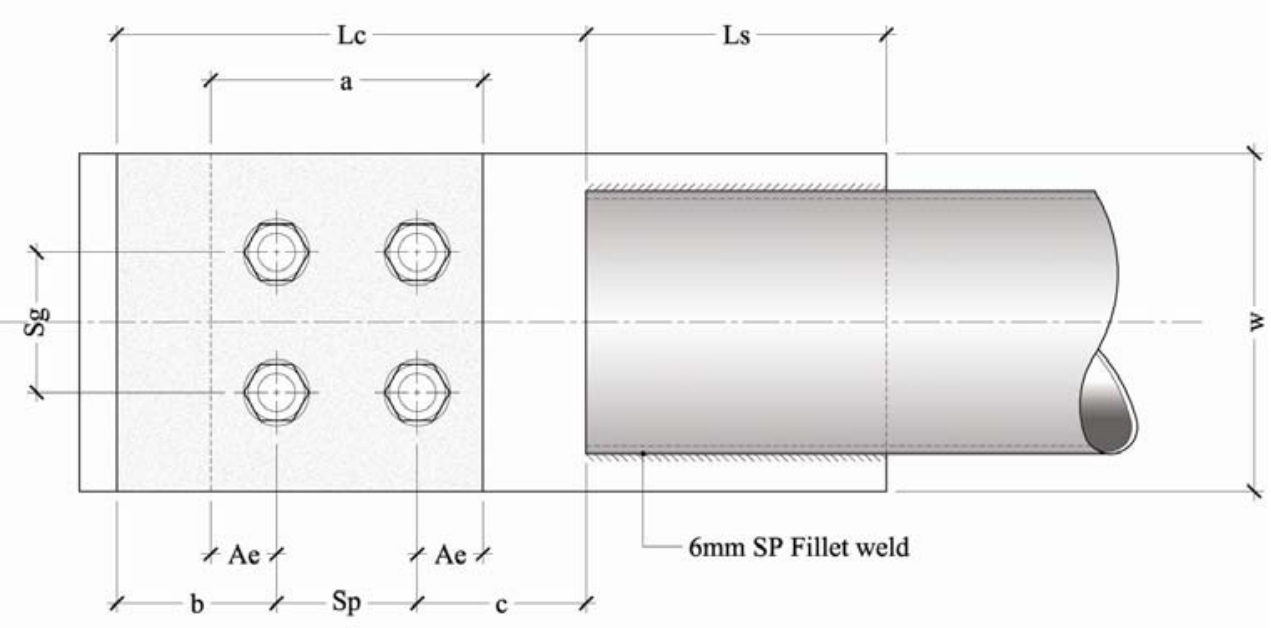

Figure 2. Dimension Nomenclature

Two coupon tests were conducted for the CHS sections and four for cleat plates. These tests indicated an average yield stress of $345 \mathrm{MPa}$ for the CHS and $320 \mathrm{MPa}$ for the cleats. Cleat connections usually require two weld locations, the first is between the slotted end plate and the supported member (the CHS member) and the second is between the gusset plate and the supporting member. The slotted end plate is usually welded along its entire slot length. For the test specimens a $6 \mathrm{~mm}$ SP fillet weld with a slotted length, $\mathrm{L}_{\mathrm{s}}$, of $260 \mathrm{~mm}$ is used (Figure 2). This weld length is adequate for even distribution of shear transfer across the slot length. Bracing members are usually connected to stiffer beams or columns. In the experimental setup used, this is achieved by welding the gusset plate to a thicker square plate $(180 \mathrm{~mm} \times 20 \mathrm{~mm})$. The weld used here is a full penetration butt weld as shown in Figure 3. The square plate is attached to a rigid support as shown in Figure 4.

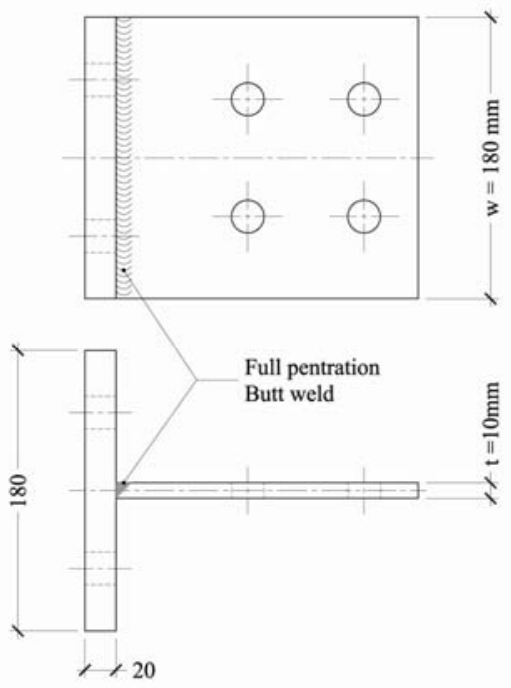

Figure 3. Supporting Cleat Common Dimensions

Good design of bolted connections requires minimizing the length of the cleat assemblies. For cleat assemblies that require two rows of bolts (Figure 2), the minimum length is comprised of the pitch distance, $S_{p}\left(70 \mathrm{~mm}\right.$ used in our samples), edge distance, $A_{e}(35 \mathrm{~mm}$ is used) and clearance to the support (minimum of $15 \mathrm{~mm}$ is used). The pitch and edge distances are governed by the size of bolt used to connect the plate. All the cleats were assembled using four M20 snug tight bolts (two rows). These length values gave a minimum cleat length, Lc, of $170 \mathrm{~mm}$. Table 1 summarizes the details for the 12 samples used in the experiment. 
The CHS member was placed horizontally in the test rig with the cleat plates oriented in the vertical plane. Figure 4 is a schematic of the test setup, Figure 5 is a photo of one of the tests and Figure 6 shows the arrangement at the loaded (a) and supported (b) ends of the test sample.

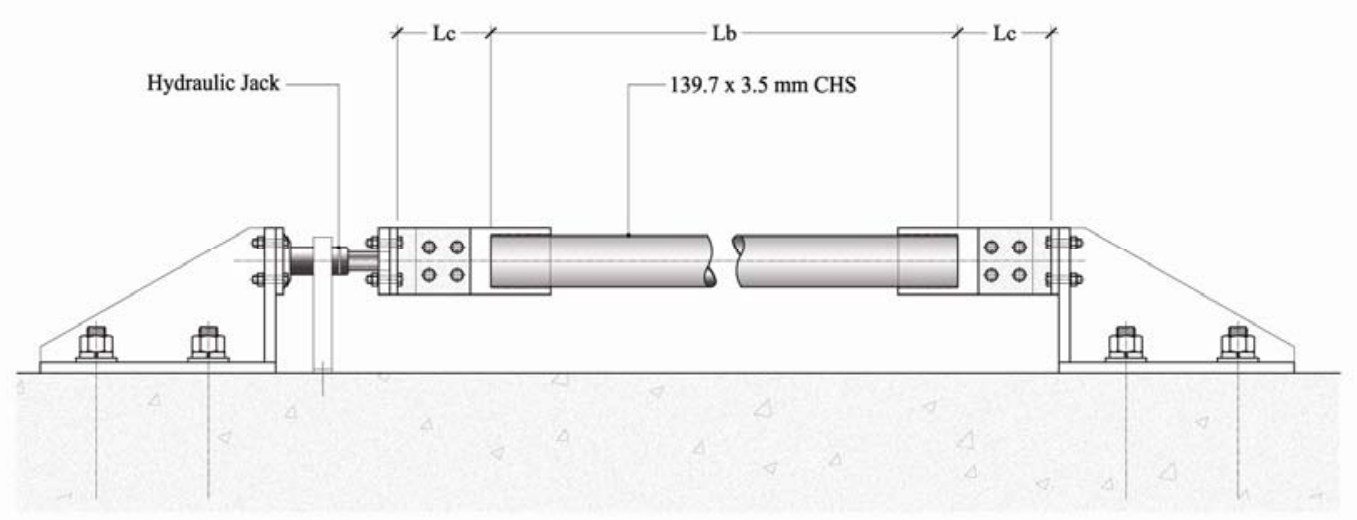

Figure 4. Testing Rig Schematic
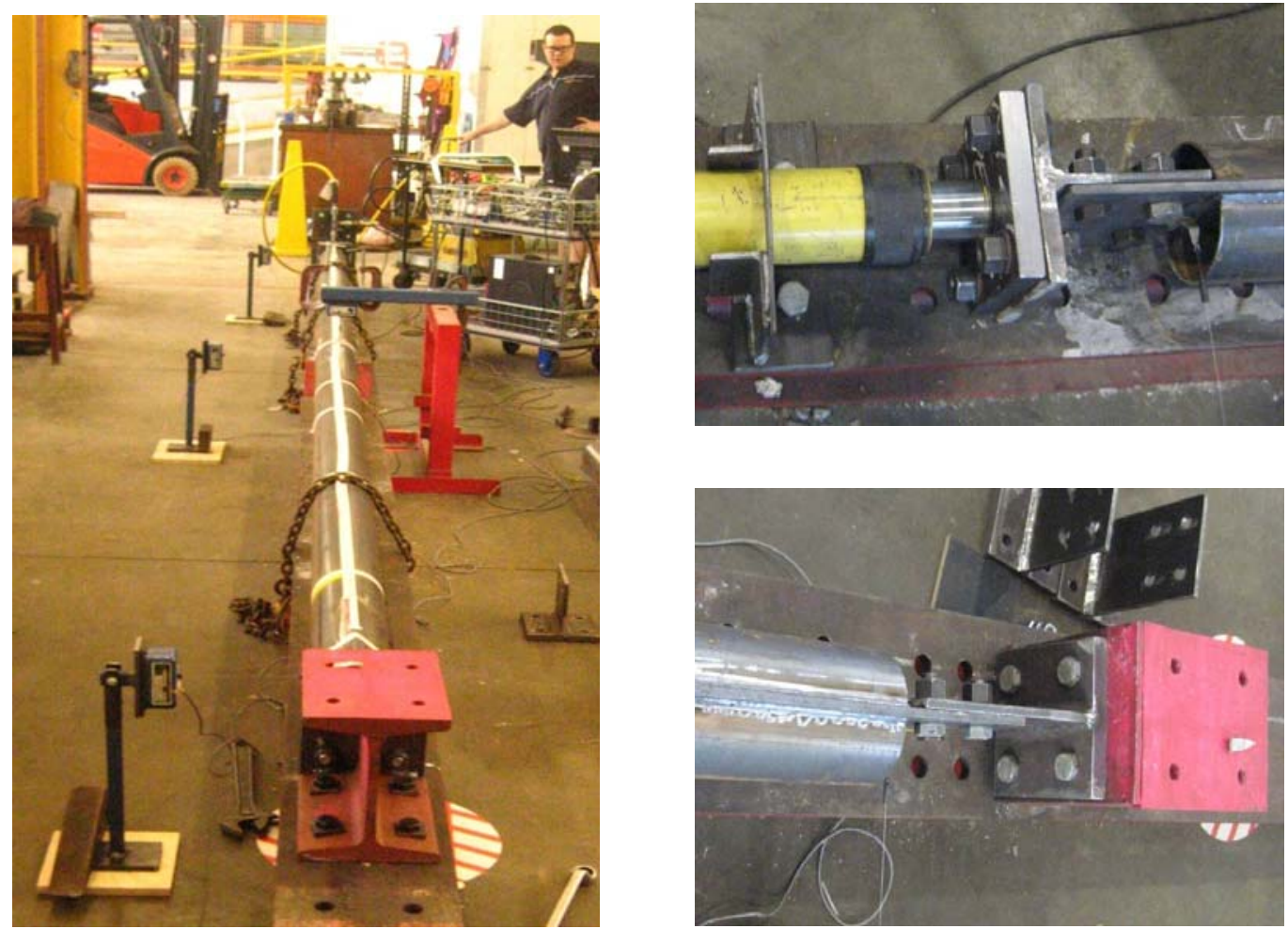

Clockwise From Left

Figure 5. Testing Rig; Figure 6. a) Support at Live End; b) Support at Fixed End

Four displacement measurements using LVDTs were recorded for each test. Two of these were placed at the interface between the slotted end plates and the CHS at each end to measure the lateral displacement and the other two at the mid-span of the CHS to measure the lateral and the vertical displacement. Similarly, strain measurements using strain gauges were recorded for four of the test samples (one for each of the $3 \mathrm{~m}, 4 \mathrm{~m}, 5 \mathrm{~m}$ and $6.5 \mathrm{~m}$ length samples). Two strain gauges were placed at opposite sides of the CHS at mid-span and the other two on the opposite sides of the slotted end plate at the supported end of the samples. 
Table 2 summarizes the test results. Nine test samples (sample A, B and C with 3, 4 and $5 \mathrm{~m}$ lengths respectively) experienced a sway collapse mechanism at the cleat connection at the supported end of the members. Figure 7 ( $a, b$ and $c$ ) shows the resulting sway collapse mechanism for $L_{c} 170,220$ and $270 \mathrm{~mm}$ respectively.

In contrast, samples D1-D3 $(6.5 \mathrm{~m})$ failed by elastic buckling of the CHS member. When taking the cleat length $\mathrm{L}_{\mathrm{c}}$ into account, samples D1-D3 have actual length of $6.84 \mathrm{~m}$. Using the experimental failure loads (Table 2) for D1-D3 and a 6.84m length, an effective length factor, k, of 0.98, 1.06 and 0.98 is obtained for D1, D2 and D3 respectively.

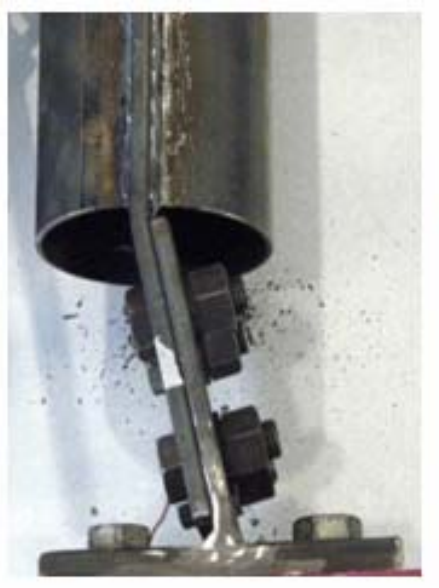

a)

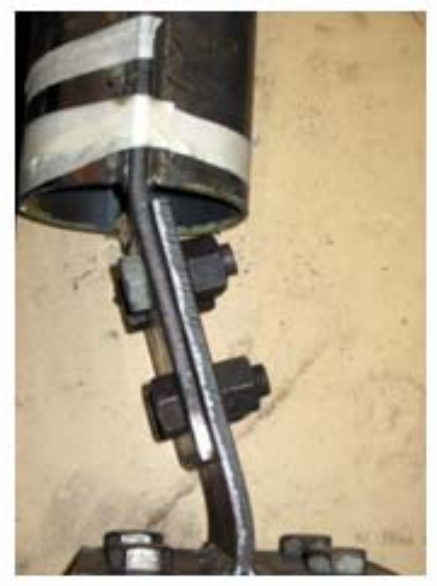

b)

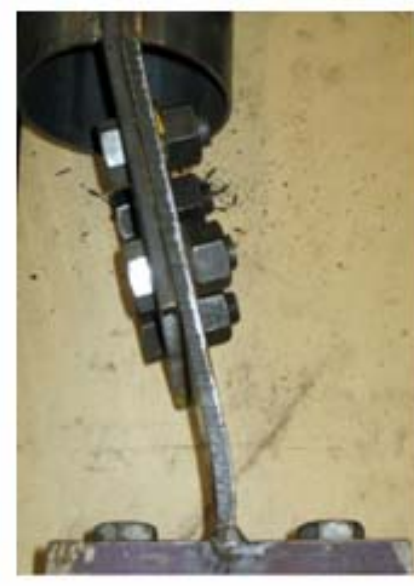

c)

Figure 7. Observed Failure Mode (a) Lc $=170 \mathrm{~mm}$ (b) Lc $=220 \mathrm{~mm}$ (c) $\mathrm{Lc}=270 \mathrm{~mm}$

Figures $8 \mathrm{a}$ and $8 \mathrm{~b}$ show some of the obtained experimental load-lateral deflection curves at mid-span for Samples A1, B1 and C1 (Figure 8a) and Samples B1-B3 (Figure 8b). From these figures, it is clear that the connection capacity is much more sensitive to the slenderness of the cleat plates (Figure 8b) rather than to the member (CHS) slenderness (Figure 8a).

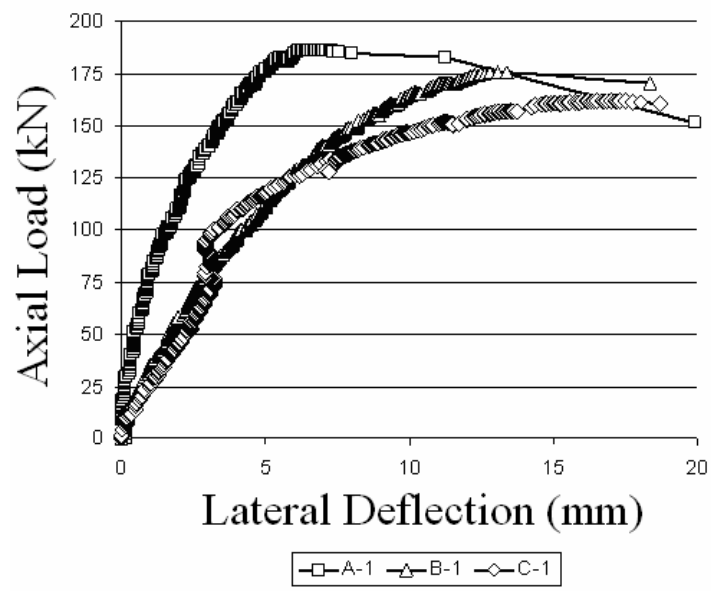

(a)

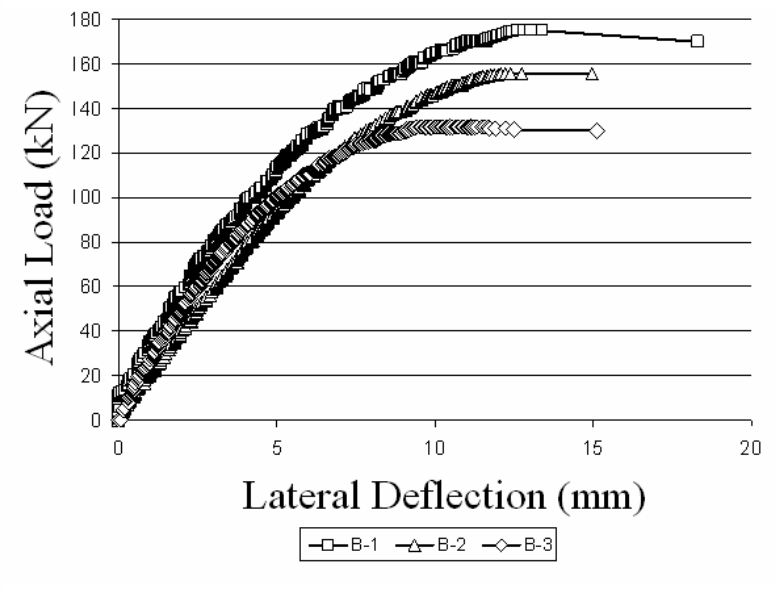

(b)

Figure 8. Axial Load Versus Lateral Deflection, (a) Varying Member Slenderness, (b) Varying Cleat Slenderness 


\begin{tabular}{|c|c|c|c|c|c|c|c|c|c|c|c|c|}
\hline & \multirow{2}{*}{$\begin{array}{c}\text { Brace } \\
\text { Length, } \\
\mathbf{L}_{\mathbf{b}} \\
(\mathrm{mm})\end{array}$} & \multicolumn{10}{|c|}{ Cleat Assembly Dimensions (mm) } \\
\hline & & & $\mathbf{L}_{\mathbf{c}}$ & $\mathbf{t}$ & $\mathbf{w}$ & $\mathbf{a}$ & b & c & $\mathrm{S}_{\mathrm{p}}$ & $\mathrm{S}_{\mathrm{g}}$ & $\mathbf{A}_{\mathbf{e}}$ & Ls \\
\hline \multirow{12}{*}{ 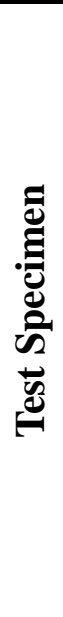 } & A-1 & 3000 & 170 & 10 & 180 & 140 & 50 & 50 & 70 & 110 & 35 & 260 \\
\hline & A-2 & 3000 & 170 & 10 & 180 & 140 & 50 & 50 & 70 & 110 & 35 & 260 \\
\hline & A-3 & 3000 & 170 & 10 & 180 & 140 & 50 & 50 & 70 & 110 & 35 & 260 \\
\hline & B-1 & 4000 & 170 & 10 & 180 & 140 & 50 & 50 & 70 & 110 & 35 & 260 \\
\hline & B-2 & 4000 & 220 & 10 & 180 & 140 & 100 & 50 & 70 & 110 & 35 & 260 \\
\hline & B-3 & 4000 & 270 & 10 & 180 & 140 & 150 & 50 & 70 & 110 & 35 & 260 \\
\hline & C-1 & 5000 & 170 & 10 & 180 & 140 & 50 & 50 & 70 & 110 & 35 & 260 \\
\hline & $\mathrm{C}-2$ & 5000 & 220 & 10 & 180 & 140 & 100 & 50 & 70 & 110 & 35 & 260 \\
\hline & $\mathrm{C}-3$ & 5000 & 270 & 10 & 180 & 140 & 150 & 50 & 70 & 110 & 35 & 260 \\
\hline & D-1 & 6500 & 170 & 10 & 180 & 140 & 50 & 50 & 70 & 110 & 35 & 260 \\
\hline & D-2 & 6500 & 170 & 10 & 180 & 140 & 50 & 50 & 70 & 110 & 35 & 260 \\
\hline & D-3 & 6500 & 170 & 10 & 180 & 140 & 50 & 50 & 70 & 110 & 35 & 260 \\
\hline
\end{tabular}

Table 1. Test Specimens Dimensions

\begin{tabular}{|c|c|c|c|c|c|}
\hline & & $\begin{array}{c}\text { Cleat } \\
\text { Slenderness } \\
(\mathbf{L c} / \mathbf{r})\end{array}$ & $\begin{array}{c}\text { Brace } \\
\text { Slenderness } \\
\text { (Lb/r) }\end{array}$ & $\begin{array}{l}\text { Experimental } \\
\text { Failure Load } \\
\text { (kN) }\end{array}$ & $\begin{array}{c}\text { Proposed Design } \\
\text { Method Predicted } \\
\text { Failure Load } \\
(\mathbf{k N}) \\
\end{array}$ \\
\hline \multirow{12}{*}{ 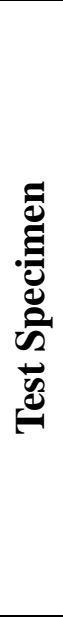 } & A-1 & 59 & 62 & 158.5 & 151 \\
\hline & A-2 & 59 & 62 & 186.1 & 151 \\
\hline & A-3 & 59 & 62 & 159.8 & 151 \\
\hline & B-1 & 59 & 83 & 175.1 & 151 \\
\hline & B-2 & 76 & 83 & 155.4 & 136 \\
\hline & B-3 & 94 & 83 & 131.4 & 119 \\
\hline & C-1 & 59 & 104 & 165.3 & 151 \\
\hline & $\mathrm{C}-2$ & 76 & 104 & 153.0 & 136 \\
\hline & $\mathrm{C}-3$ & 94 & 104 & 115.5 & 119 \\
\hline & D-1 & 59 & 135 & 141.0 & - \\
\hline & D-2 & 59 & 135 & 131.0 & - \\
\hline & D-3 & 59 & 135 & 140.0 & - \\
\hline
\end{tabular}

Table 2. Test Specimen Experimental and Predicted Failure Loads

\section{COMPARISON OF EXPERIMENTAL RESULTS WITH DESIGN METHODS}

The experimental results are compared with the ASI [1] and HERA [8] design methods and with results from connection design software LIMCON V3 [5]. Generally ASI predictions grossly overestimate the connection capacity since it excludes sway failure mechanism. When comparing the predicted ASI results for the nine samples (A, B and C) that were governed by connection failure, on average the ASI overestimates the capacity by $53 \%$. 
When comparing the results for the nine samples (A, B and C) with the design method proposed by HERA [8], it appears that HERA design capacity predictions are on the safe side. The ratios of the predicted capacity using HERA to the experimental results range from 0.48 to 0.70 with an average ratio of 0.56 for the nine samples. The conservatism in HERA approach stems from a number of reasons. For example HERA recommends using an additional $3 \mathrm{~mm}$ eccentricity for the cleat plates (for the sample tested with $10 \mathrm{~mm}$ thick cleats, this amount to $30 \%$ increase in the resulting moment). Furthermore, HERA method use the elastic section modulus to evaluate the moment capacity of the cleat plates and HERA approach has been developed with seismic actions in mind.

On the other hand, the correlation between the capacities predicted by LIMCON [5] and the experimental results is very good. The capacity ratios (LIMCON to experiment) ranged from 0.77 to 0.95 with an average ratio of 0.85 . LIMCON method follows the recommendations in AS 4100 [7] for combined actions design where second-order effects are accounted for through moment magnification. It incorporates a design capacity factor $\varphi=0.9$. Taking the experimental results as nominal capacities, a more realistic comparison with Limcon can be obtained by dividing Limcon prediction by $\varphi$. Accordingly, the average capacity ratio is revised to $0.85 / \varphi=0.94$.

\section{PROPOSED DESIGN METHOD}

Based on the experimental observations presented earlier, the sway collapse mechanism (Figure 7) is the governing mechanism that determines the connection capacity. A two steps design method for eccentric cleat connection in compression is proposed in this section. A schematic of the sway mechanism with two plastic hinges is shown in Figure 9, the external work V (ignoring second-order effects) is

$\mathrm{V}=\mathrm{P}$ e $\theta$

Where $\mathrm{P}$ is the applied load, e is the load eccentricity which equals the average thickness of the supported and supporting cleat plates (see Figure 1a) and $\theta$ is the rotation as shown in Figure 9.

The internal energy, $U$, is

$\mathrm{U}=\left(\mathrm{M}_{\mathrm{p} 1}+\mathrm{M}_{\mathrm{p} 2}\right) \theta$

Where $\mathrm{M}_{\mathrm{p} 1}$ and $\mathrm{M}_{\mathrm{p} 2}$ are the plastic moments of the supported and supporting cleat plates respectively (for identical cleat plates with $\sigma_{y}$ yield stress, $M_{p 1}=M_{p 2}=M_{p}=\sigma_{y} w t^{2} / 4$ ).

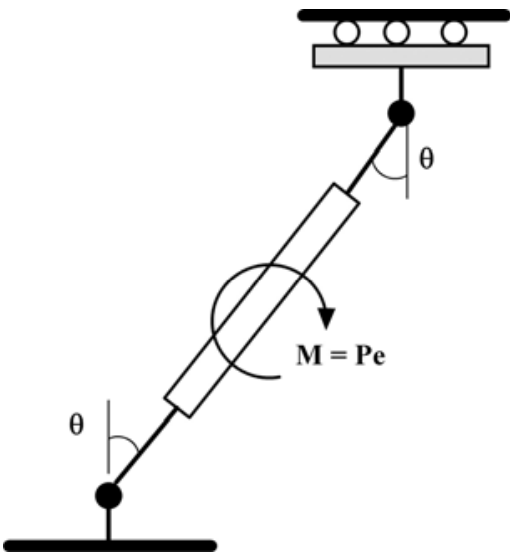

Figure 9. Sway Type Collapse Mechanism 
Equating the external and internal energies (Eqs. 1 and 2) and assuming identical supporting and supported cleat plates, the collapse load, $\mathrm{P}$, for the connection can be obtained

$\mathrm{P}=2 \mathrm{M}_{\mathrm{p}} / \mathrm{t}$

A non dimensional collapse load, $\eta$, is obtained by normalizing the load $\mathrm{P}$ from Eq. 3 by $\mathrm{P}_{\mathrm{y}}$ (cleat's squash load, $\mathrm{P}_{\mathrm{y}}=\sigma_{\mathrm{y}} \mathrm{wt}$ )

$\eta=P / P_{y}$

The elastic buckling load, $\mathrm{P}_{\mathrm{EC}}$ of the cleat, assuming sway mode, is calculated

$P_{E C}=\frac{\pi^{2} E I_{c}}{\left(1.2 L_{c}\right)^{2}}$

Where $\mathrm{E}$ is the elasticity modulus, $\mathrm{I}_{\mathrm{c}}$ is the cleat plate moment of inertia $\left(\mathrm{wt}^{3} / 12\right)$ and $\mathrm{L}_{\mathrm{c}}$ is the cleat plate length as shown in Figure 2. Depending on slenderness ratio, the critical buckling load $\mathrm{P}_{\mathrm{C}}$ is given by [4]

$$
\begin{aligned}
& \Lambda>\sqrt{2} \rightarrow P_{C}=P_{E C} \\
& \Lambda \leq \sqrt{2} \rightarrow P_{C}=P_{y}\left(1-\frac{P_{y}}{4 P_{E C}}\right)
\end{aligned}
$$

Where,

$$
\Lambda=\left(\frac{P_{y}}{P_{E C}}\right)^{0.5}
$$

The ultimate load $\mathrm{P}_{\mathrm{U}}$ of the connection can be obtained from;

$$
P_{U}=\frac{P_{C}}{1+\frac{P_{C}}{\eta P_{y}}}
$$

Once the ultimate load is calculated from Eq. 8, a second (and last) step starts by modifying the plastic moment to account for the effect of the axial load $\mathrm{P}_{\mathrm{U}}$ in the connection

$M_{p}=M_{p}\left[1-\left(\frac{P_{U}}{P_{C}}\right)^{2}\right]$

The revised plastic moment $M_{p}$ from Eq. 9 is used to obtain a new collapse load $P$ from Eq. 3 , a new factor $\eta$ from Eq. 4 and a revised ultimate load using Eq. 8 (in the $2^{\text {nd }}$ step, $P_{y}, P_{E C}, P_{C}$ and $\Lambda$ remain unchanged from the $1^{\text {st }}$ step).

The ultimate loads predicted by the proposed approach for the test samples used in the current experiment are listed in Table 2. The proposed method gives a good estimate of the connection capacity compared to test results. 


\section{PARAMETRIC STUDY OF CLEAT CONNECTIONS}

A parametric study for cleat connections using various combinations of cleat length $\mathrm{L}_{\mathrm{c}}$, thickness, $\mathrm{t}$, and width, w, was conducted using three approaches. These are; nonlinear finite element analysis of the cleat using Strand7 software [10], modeling using connection design software LIMCON and the proposed design method. In the nonlinear FE analysis, both the cleat plates and the CHS member are modeled using an assembly of beam elements and an elastic-perfectly plastic material representation is used.

Figure 10 shows the results from the parametric study. The failure load is normalized by the cleat squash load $\mathrm{P}_{\mathrm{y}}$ and presented as a function of the cleat slenderness ratio $\mathrm{L}_{\mathrm{d}} / \mathrm{r}$. The three points shown in this figure are the experimental results, each point represents the average of three experimental results from specimens A, B and C. Generally a good agreement is obtained between the proposed design method, the experimental results, the numerical (FE) analysis and LIMCON results. As was explained before, Limcon results shown in Figure 10 were obtained by dividing Limcon predictions by $\varphi=0.9$.

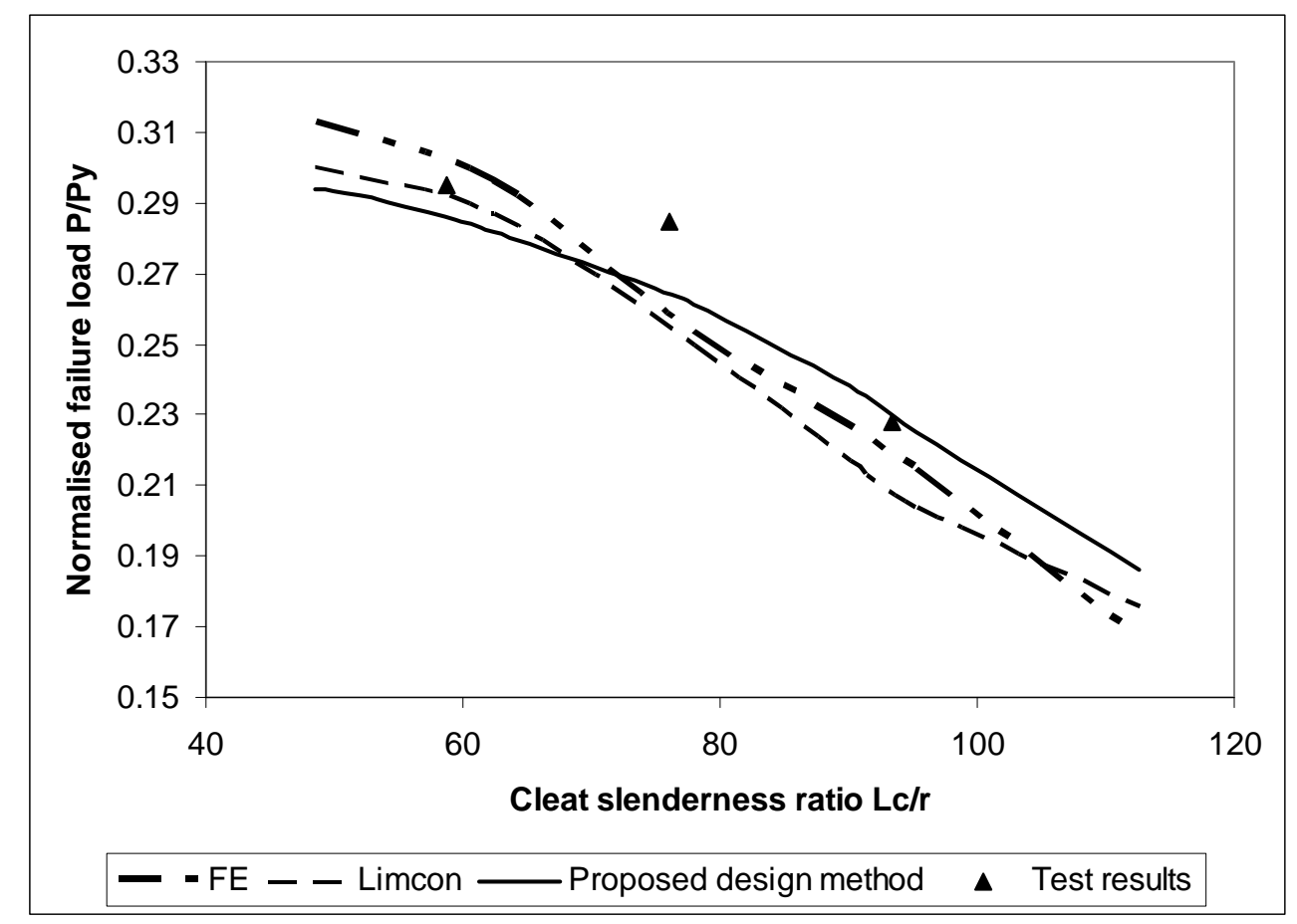

Figure 10. Parametric Study: Variation of Failure Load with Cleat Slenderness Ratio

\section{CONCLUSION}

The results from 12 full scale test samples using different member lengths and eccentric cleats combinations were presented in this paper. These results were compared with available design methods and FE results. Based on the experimental observations, the governing connection failure is a sway collapse mechanism. A simple two steps design method for cleat connection design is proposed. A good agreement between results from the proposed design method, experiments and FE predictions is obtained. 


\section{ACKNOWLEDGEMENTS}

The authors would like to acknowledge the financial assistance towards the experimental program made by Bonacci Group Consulting Engineers, in particular the support of Dr Scott Woolcock. The CHS members were donated by Smorgon Steel Tube Mills, Brisbane. The support of Mr Richard Collins of LIMCON/Engineering Systems Pty Ltd is appreciated. Finally, the assistance of $\mathrm{Mr}$ Fraser Reid of the Structures Lab at the School of Civil Engineering, The University of Queensland, in conducting the experimental work is acknowledged.

\section{REFERENCES}

[1] Syam, A.A. and Chapman, B.G., "Design of Structural Steel Hollow Section Connections", ASI, 1996.

[2] AISC, "Hollow Structural Sections Connections Manual", American Institute of Steel Construction, 1997.

[3] CSA, Canadian Standards Association, CAN/CSA-S16-01, "Limit States Design of Steel Structures", 2003.

[4] Kitipornchai, S., Albermani, F. and Murray, N., "Eccentrically Connected Cleat Plates in Compression", Journal of Structural Engineering, ASCE, Vol. 119, No. 3, 1993.

[5] Limcon V3, "Limit State Design of Steel Connections", Engineering Systems Pty Ltd, www.steel-connections.com

[6] ASI Advisory Note, "Design Method for Eccentrically Connected Cleats Not to be Used", Australian Steel Institute ASI Journal, Vol. 39, No. 2, 2005.

[7] Standards Australia, AS4100 Steel Structures, 1998.

[8] Clifton, C. and Sarraf, R. El., "Eccentric Cleats in Compression and Columns in Moment Resisting Connections", New Zealand Heavy Engineering Research Association (HERA, www.hera.org.nz ), 2007.

[9] Stock, D., "Eccentric Cleat Plate Connections in Hollow Section Members in Compression", Department of Civil Engineering, The University of Sydney, 2007.

[10] G+D Computing, Strand7 Software, www.strand7.com 